\title{
Golden ratio in congestive heart failure: A promising proportion for prognosis and decompensation
}

\author{
Ertan Yetkin ${ }^{1}$, Selcuk Ozturk², Bilal Cuglan ${ }^{3}$, Hasan Turhan ${ }^{1}$ \\ ${ }^{1}$ Istinye University Liv Hospital, Department of Cardiology, Istanbul, Turkey \\ ${ }^{2}$ Ankara Education and Research Hospital, Cardiology Clinic, Ankara, Turkey \\ ${ }^{3}$ Beykent University, Faculty of Medicine, Department of Cardiology, Istanbul, Turkey
}

The article published by Kowalczys et al. [1] was read with great enthusiasm and interest. Briefly, the prognostic value of daytime heart rate (HR), systolic (SBP) and diastolic (DBP) blood pressure (BP), and their multiplication products and ratios was assessed in congestive heart failure (CHF) patients. Accordingly, it was found that daytime $\mathrm{DBP}$ and products including $\mathrm{HR} \times \mathrm{DBP}$ and $\mathrm{HR}$ $\times$ SBP may be valuable risk stratification factors for predicting death and decompensation in stable patients [1]. Beyond the prognostic implication of $\mathrm{HR}, \mathrm{BP}$ and their products in patients with stable CHF, attention was paid to the value of SBP and DBP itself, in terms of the golden ratio. In the study population, Kowalczys et al. [1] found mean daytime SBP and DBP of patients with stable $\mathrm{CHF}$ as $114 \mathrm{mmHg}$ and $70 \mathrm{mmHg}$, respectively. The ratio of SBP to DBP gives 1.62 , which is very close to the golden ratio as described previously by the famous mathematicians Euclid and Fibonacci [2]. In addition, it is also noteworthy to calculate the ratio of SBP to DBP in patients with decompensated $(107.0 / 60.7 \mathrm{mmHg})$ and non-decompensated $(115.3 / 72.1 \mathrm{mmHg})$ status during the follow-up period. SBP/DBP in patients without decompensation is 1.59; whereas it is 1.76 in decompensated patients, which shows a distinct deviation from the golden ratio.

In principle, golden proportion is an observation that the ratio of any two sequential Fibonacci numbers approximates to the value of 1.618 , which is named as the Greek letter Phi $(\varphi)$ [2]. The Fibonacci series or golden ratio represents itself in a variety of natural settings such as the design of patterns in flowers, branching of leaves; and have also been used in the modeling of biological and financial systems as well as in electronics and music [2-4]. By defining the systolic phase interval as the time between the tip of the $\mathrm{R}$ wave and the end of the $\mathrm{T}$ wave on electrocardiography, the diastole/ /systole ratio has demonstrated as 1.611 and R-R interval/diastole ratio as 1.618 , which is very close to golden ratio [5]. Furthermore, the ratio of the left ventricular end-diastolic to the end-systolic diameters gives a ratio equal to 1.614 , which is quite close to the golden ratio [6]. In a similar manner, Henein et al. [7] have demonstrated that vertical and transverse dimensions of the heart are in accordance with the golden ratio in healthy humans. However, in the end-stage $\mathrm{HF}$ patients the ratio significantly decreases [7]. Likewise, SBP to DBP ratios have been shown to be very close to the golden ratio both in the systemic and pulmonary vascular system [8-10]. Yetkin et al. [8] observed that night-time proportions of systemic systolic to diastolic pressures are the closest results to the golden ratio; however, during the daytime it is a bit far from the golden ratio which might be explained by the changing balance between sympathetic and parasympathetic activity [8]. In this regard, it is exciting to observe the SBP/DBP ratio as very close to the golden proportions in stable $\mathrm{CHF}$ and deviated in decompensated patients. Values of the SBP/DBP rate, which are higher than or show considerable deviation from the golden ratio, might be a useful criterion for predicting decompensation in stable $\mathrm{CHF}$ patients with the support of future clinical studies.

Conflict of interest: None declared

Address for correspondence: Dr. Selcuk Ozturk, Ankara Education and Research Hospital, Cardiology Clinic, Ulucanlar Street, 06230, Ankara, Turkey, tel: +905535376613, e-mail: selcukozturk85@hotmail.com 


\section{References}

1. Kowalczys A, Bohdan M, Gruchała M. Prognostic value of daytime heart rate, blood pressure, their products and quotients in chronic heart failure. Cardiol J. 2019; 26(1): 20-28, doi: 10.5603/ CJ.a2017.0130, indexed in Pubmed: 29131282.

2. Persaud-Sharma D. O'Leary J. Fibonacci series, golden proportions, and the human biology. Austin J Surg. 2015; 2(5): 1-7.

3. Yalta K, Ozturk S, Yetkin E. Golden ratio and the heart: A review of divine aesthetics. Int J Cardiol. 2016; 214: 107-112, doi: 10.1016/j.jicard.2016.03.166, indexed in Pubmed: 27060268.

4. Ozturk S, Yalta K, Yetkin E. Golden ratio: A subtle regulator in our body and cardiovascular system? Int J Cardiol. 2016; 223: 143-145, doi: 10.1016/j.ijcard.2016.08.147, indexed in Pubmed: 27537743

5. Yetkin G, Sivri N, Yalta K, et al. Golden ratio is beating in our heart. Int J Cardiol. 2013; 168(5): 4926-4927, doi: 10.1016/j. ijcard.2013.07.090, indexed in Pubmed: 23890853.
6. Yetkin E, Çelik T, Arpaci M, et al. Left ventricular diameters as a reflection of ,extreme and mean ratio”. Int J Cardiol. 2015; 198: 85-86, doi: 10.1016/j.ijcard.2015.06.164, indexed in Pubmed: 26156320 .

7. Henein MY, Zhao Y, Nicoll R, et al. The human heart: application of the golden ratio and angle. Int J Cardiol. 2011; 150(3): 239-242, doi: 10.1016/j.ijcard.2011.05.094, indexed in Pubmed: 21703707.

8. Yetkin E, Topbaş U, Yanik A, et al. Does systolic and diastolic blood pressure follow Golden Ratio? Int J Cardiol. 2014; 176(3): 1457-1459, doi: 10.1016/j.ijcard.2014.08.065, indexed in Pubmed: 25150476.

9. Chemla D, Boulate D, Weatherald J, et al. Golden ratio and the proportionality between pulmonary pressure components in pulmonary arterial hypertension. Chest. 2019; 155(5): 991-998, doi: 10.1016/j.chest.2018.12.006, indexed in Pubmed: 30594558.

10. Yetkin E, Çuğlan B, Turhan $\mathrm{H}$, et al. Does golden ratio reside in pulmonary circulation? Chest. 2019; 156(3): 629-630, doi: 10.1016/j.chest.2019.04.112, indexed in Pubmed: 31511152. 